\title{
Measuring resilience to economic shocks: an application to Spain
}

\author{
Angulo AM, Mur J, Trívez FJ \\ Universidad de Zaragoza \\ Gran Vía 2, 50.005 Zaragoza \\ Corresponding author: Angulo AM (aangulo@unizar.es)
}

\begin{abstract}
$\underline{\text { Abstract }}$
In this paper, we evaluate Spanish regions' resistance to the economic crisis under three main resilience notions: “Adaptative”, “Engineering” and "Ecological”. “Adaptative” resilience is measured through a traditional shift-share approach applied to employment, whereas "Engineering” and "Ecological” resilience pay attention to growth path and total employment level, in the pre- and post-crisis period. The paper presents an application of the different notion of resilience to the case of Spanish provinces in the last years. We find that provinces with sectoral structure and location advantages, or those with locational advantages in the post-crisis period (according to the "Adaptative" resilience measure), exhibit a significantly lower "drop" in growth (according to the "Engineering" and "Ecological” resilience measure). Furthermore, we conclude that the probability of presenting a better behavior (lower "drop" in growth than the average) increases for those regions specialized in the service sector before the crisis. As expected, the worse behavior has corresponds to those regions specialized in the pre-crisis period in the construction sector.
\end{abstract}

Keywords: “Adaptative”, "Engineering” and "Ecological” resilience, shift-share analyses, spatial panel data model, specialization.

JEL Classification: C21; C22; C23; C53; R15.

\section{Acknowledgement}

The authors are grateful for the financial support of the Spanish Government's Ministry of Economy and Competitiveness (ECO2015-65758-P), as well as for the financial support of the Department of Industry and Innovation of Aragon Government and the European Fund of Regional Development through the GAEC group. 


\section{Measuring resilience to economic shocks: an application to Spain}

\section{Introduction}

Recent literature has popularized the term "resilience" which refers to the ability of a local socio-economic system to recover from a shock or disruption as could be financial crises, epidemics, natural disasters, etc. Foster (2007) defines regional resilience as "the ability of a region to anticipate, prepared for, respond to, and recover from a disturbance”. Similarly, Hill et al. (2008) define resilience as "the ability of a region... to recover successfully from shocks to its economy that either throw it off its growth path or have the potential to throw it off its growth path.

In the cases of shocks like economic and environmental crises, because of their global and interconnected character, spatial economics turns to be very useful for the assessment of regional resilience. A nice literature revision on this topic can be found in Modica and Reggiani (2015).

Two main resilience notions, known as “Engineering” and "Ecological” resilience, are depicted in Figure 1. "Engineering” resilience (Figure 1a) relates to regional economic rebound. The only requisite for this category is the return to the pre-existing position or to the path it would have been in the absence of the shock. In this view, recessionary shocks should be transitory, and should have no permanent effect on the economy's long-run growth ceiling or growth trend. Hence, the focus of this approach is on resistance to shocks and stability near equilibrium.

\section{(Insert Figure 1)}

"Ecological" resilience measures the shock that can be absorbed before the system changes its form, function or position (Holling, 1973, 1996, 2001; McGlade et al., 2006; Walker et al., 2006). This approach is related to the concept of "hysteresis", which is defined as a situation where disturbances permanently affect the path of the economy (Romer, 2001). Hence, "Ecological” resilience is measured by comparing pre-shock and post-shock (stable) state. More precisely, if the situation of certain economy after a shock is "worse" than its position before the shock, then it presents low resilience or negative hysteresis. These are the cases depicted in Figures 1b and Figures 1c. Figure 1b represents a recession that permanently lowers the level of employment or output, although the region's growth rate recovers its preshock rate (the region's economy is able to resume its pre-recession growth rate, but on a 
permanently lowered trend path). Figure 1c shows the case where both, the region's level of output or employment, and its post-shock growth rate, is lowered. In the opposite side, we will refer to high "Ecological" resilience to shocks, or positive hysteresis, if after a recessionary shock the economy is able to move to a "superior" state. Some examples are depicted in Figures 1d and 1e. In both cases, the regional economy more than "rebounds" from the recessionary downturn, and initially experiences rapid growth out of the recession, at a rate above the pre-shock growth rate. However, while in the case of Figure $1 \mathrm{~d}$ growth rate resumes to pre-recession level, in the case of Figure 1e the recovery takes place to a sustained higher growth rate.

In this context, Martin (2012) coined a third resilience term, called "Adaptative" resilience, in reference to the capacity of a region to reconfigure itself; that is, to adapt its structure (firms, industries, technologies and institutions) so as to maintain an acceptable growth path in employment, output or wealth over time. It is assumed that after a recession, a region will be high/low “Adaptative” resilient depending on its ability to develop higher/lower productive sectors than those swept away by the recession.

Literature has integrated the three resilience notions. Modica and Reggiani (2015) indicate that "Engineering resilience" seems more related to conventional global stability theory while “Adaptative” resilience can be conceived as an insightful interpretation of "Ecological” resilience. Nevertheless, there remains a lot of work to be done. For instance, Martin (2012), and Martin and Sunley (2015) claim for clearer definitions, whereas Modica and Reggiani (2015) ask for a more consistent analytical framework to achieve a clear understanding and representation of the evolutionary of spatial economic processes (“Ecological resilience”).

The severe consequences of the recent crisis that has hit the World economy, and the Spanish in particular, has been our main motivation. In this context, this paper aims two objectives. First, we pursue to get insight into consistent analytical framework to determine whether a specific (Spanish) region present low or high resilience. Second, after classifying the provinces into categories according to resilience to recent downturn, we try to derive more general conclusion about how the three notions are related. To accomplish this goal, various probit models are estimated to measure whether well-behaved (wrong behaved) regions, in

\footnotetext{
1 "Ecological" resilience is related to evolutionary theories, which consider the region as the result of social interactions subject to a process of transition and time is considered a flow.
} 
terms of "Adaptative” resilience, are likely to be also well-behaved (wrong behaved) under the two other resilience notions. Our conclusion in this point is that the results for each notion must be understood under the framework under which they have been derived. However, in general, they are related: the best behaved regions under the "Adaptative” resilience notion are also the most likely to behave properly in term of the "Engineering”/ "Ecological” perspectives.

The methodological approach to resilience range from descriptive, interpretative case studies to sophisticated statically and econometric models. Among them, we can find case studies such as Evans and Karecha (2013); simple indices, such as Martin (2012) or Augustine et al. (2013); statistical time series models as in Fingleton et al. (2012); and finally, causal structural models, such as Doran and Fingleton (2013) or Fingleton and Palombi (2013). In our proposal, we are going to approach the "Adaptative” notion of resilience through two shift-share analyses (one for the pre-crisis period, the other for the post-crisis period). Moreover, “Engineering”/“Ecological” resilience will be measured, following Fingleton and Palombi (2013) by comparing the counterfactual (or projected) annual growth rate of employment in absent of the economic crisis with the actual ones ${ }^{2}$.

Empirical evidence is obtained from quarterly employment provincial data in the four main economic sectors (agriculture, industry, construction and services), for the period 2002:1-2015:4 in Spain. Before launching this study, we have to estimate the time of the shock for the Spanish economy, which is in the second quarter of 2008, 2008:2. Then, as regards "Adaptative" resilience, we derive two shift-share analyses to conclude on regional behavior before and after the shock. From Industrial Mix (IM) and Regional Share (RS) components, regions are classified among categories I to IV (from best to worst behavior) before and after the crisis. Furthermore, the specialization pattern before and after the crisis is also obtained. According to this approach, a region will be considered high resilient if it has maintained, or even improved, its performance after the shock through a sectoral restructuration. Results show that some provinces such as Malaga, A Coruña, Lugo, Gipzzkoa, Palencia or Madrid, among others, can be considered high resilient within this perspective.

\footnotetext{
${ }^{2}$ Nevertheless, our counterfactual predictions are obtained through a different process that that proposed in Fingleton and Palombi (2013).
} 
Concerning “Engineering”/“Ecological” resilience, we will pay attention to both total employment growth and level of employment in the pre- and post-crisis periods. Since the shock for the Spanish economy is identified in 2008:2, we estimate a panel data model for the pre-shock period for the annual growth rate of total employment. Afterwards, using these estimates, we forecast total employment growth rates for the Spanish provinces for the postcrisis period. The predicted values for each province represent the counterfactual (or projected) annual growth rate of employment, in absence of the economic crisis. The idea is that forecasted values purged of the effect of the shock ${ }^{3}$. Finally, we measure the effect of the crisis by comparing forecasted and actual values. According to these differences, the “Engineering” notion classifies a province as high resilient only when its actual employment growth and level are statistically the same as the forecasted one (as in Figure 1a). In an analogous way, under the "Ecological” perspective, a province is classified as high resilient in two cases: i) its actual growth is significantly higher than the forecasted one (as in Figure 1e); or ii) its actual growth is statistically the same as the forecasted one but the employment level is higher than the predicted one in absent of the crisis (as in Figure 1d). In any other case, the respective province will be classified as low resilient. Results indicate that all Spanish provinces can be considered as low resilient.

“Adaptative” versus “Engineering”/“Ecological” resilience results are different. However, since they rely on different hypothesis, the key issue is to determine whether or not they are connected. To answer this question, first, let's define a dummy variable which takes the value 1 for those provinces that present a better behaviour than the national average, and zero otherwise, according to the "Engineering”/“Ecological” perspective. The dummy variable so created will be the endogenous term of a probit model whose explicative variables describe “Adaptative” resilience in the province. Results are clear: higher resilient provinces (according the "Adaptative" perspective) are more likely to have also a better behaviour than the rest (according to the two other perspectives). Furthermore, results reveal that an adequate specialization strategy in the past does not have a significant effect in this equation.

Finally, to gain further insight into the specialization role, we analyse the relationship between specialization and "Engineering"/“Ecological” resilience through the assessment of the effect on resilience of the sectoral specialization of the region. In fact, our purpose is in

\footnotetext{
${ }^{3}$ They are represented as dotted lines in graphs in Figure 1.
} 
line with the work of Cuadrado-Roura and Maroto (2016) who also relate resilience to regional productive specialization and productivity.

In our case, provincial specialization is measured by the location quotients, obtained for each quarter of the sample. Next, we average location quotients for each of the two periods (pre- and post- crisis) and for the four main economic sectors: agriculture, construction, industry and services. Results are clear: the specialization in the pre-crisis period in the construction sector reduces the probability of presenting a good performance in term of the "Engineering”/“Ecological” resilience; the opposite takes place for provinces specialised in the service sector. Specialization in agriculture and industry sector are positive but not significant.

The structure of the paper is as follows. Section 2 shows the methodology for accomplish the measure for the three resilience notions. Section 3 is devoted to employment data used in the analysis. Section 4 shows the results obtained for the three approaches to resilience as well as its relations. Finally, the paper finishes with a Section of conclusions.

\section{Methodology}

As explained before, the first step in our proposal is to identify the time in which the shock occurs for the Spanish case. This will allow us to define the pre-crisis (till the shock happens) and the post-crisis period (from the shock onwards). Next, we will proceed to measure the three resilience notions as explained below.

\section{1. “Adaptative” resilience: shift-share analyses}

“Adaptative” resilience refers to the capacity of an economy to reconfigure, that is, to adapt its structure so as to maintain and acceptable growth path. We approach this issue by means of two shift-share analyses. The goal of the first is to identify the main factors affecting for employment growth in the pre-crisis period, while the second will analyse the path of growth in the post-crisis period.

As it is well-known, shift-share analysis is a technique to identify the factors underpinning geographical variations in employment growth. Basically, it consists on examining the interdependencies of a subarea with the parent area, trying to identify the principal components of growth. First, we will decompose the temporal change in a 
province’s employment over a given period into three additive components: National Share (NS), Industry Mix (IM) and Regional Share (RS). Formally, denoting by $L_{i}^{r}(t)$ the level of employment in sector $i(\mathrm{i}=1, \ldots \mathrm{S})$ in province $r(\mathrm{r}=1, \ldots, \mathrm{R})$ in period $t(\mathrm{t}=1, \ldots, \mathrm{T})$, a temporal change in employment in sector $i$ and province $r$ between $t$ and $t+m$ can be decomposed as:

$$
\Delta L_{i}^{r}(t+m)=L_{i}^{r}(t+m)-L_{i}^{r}(t)=N S_{i}^{r}(t+m)+I M_{i}^{r}(t+m)+R S_{i}^{r}(t+m)
$$

Where each of these three components can be expressed as follows:

$$
\begin{aligned}
& N S_{i}^{r}(t+m)=r_{\bullet}^{\bullet} L_{i}^{r}(t) \\
& I M_{i}^{r}(t+m)=\left[r_{i}^{\bullet}-r_{\bullet}^{\bullet}\right] L_{i}^{r}(t) \\
& R S_{i}^{r}(t+m)=\left[r_{i}^{r}-r_{i}^{\bullet}\right] L_{i}^{r}(t)
\end{aligned}
$$

being

$r_{\bullet}^{\bullet}=$ the national (percentage) growth of employment between $\mathrm{t}$ and $\mathrm{t}+\mathrm{m}$.

$r_{i}^{\bullet}=$ the national (percentage) growth by sector $i$ of employment during this period.

$r_{i}^{r}=$ the provincial (percentage) growth by sector $i$ of employment during this period.

The National Share of sector $i$ represents the change in employment due to the national growth effect; is measured assuming that all sectors in a province are growing at the same national rate. The Industry Mix for sector $i$ represents the employment growth induced by the specific economic structure. It is measured evaluating the provincial employment growth due to the differences between the sectoral national growth rates and the average national rate. Finally, the Regional Share of sector $i$ is the difference between the actual change and the sum of national and industry shares. It captures provincial-specific factors such as positive (or negative) externalities arising from agglomeration effects, local labor force characteristics, local incentives, locational advantages, environment, etc.

By summing over all sectors in a province, we arrive at the aggregated national, industrial mix and regional share components for province $r$, as follows:

$$
\begin{aligned}
& N S^{r}(t+m)=\sum_{i=1}^{S} r_{\bullet}^{\bullet} L_{i}^{r}(t) \\
& I M^{r}(t+m)=\sum_{i=1}^{S}\left[r_{i}^{\bullet}-r_{\bullet}^{\bullet}\right] L_{i}^{r}(t) \\
& R S^{r}(t+m)=\sum_{i=1}^{S}\left[r_{i}^{r}-r_{i}^{\bullet}\right] L_{i}^{r}(t)
\end{aligned}
$$


The overall national component, $N S^{r}(t+m)$, measures the national trend common to all Spanish provinces. The overall industrial mix, $I M^{r}(t+m)$, measures employment growth generated by the economic structure of province $r$. If a province $r$ presents a positive industrial mix means that it is specialized in dynamic sectors $\left(r_{i}^{\bullet}>r_{\bullet}^{\bullet}\right)$ and consequently, it is likely to present a positive growth for the aggregated employment. Finally, the regional share reflects the extent to which the growth rate of the whole set of sectors improves, or not, the national counterpart. Hence a positive regional share reflects positive provincial externalities that contribute to impulse sectoral employment growth above the national sectoral average.

The combination of industrial mix and regional shares allows us classifying each province in one of the four categories displayed in Table 1. Provinces in Category I combine advantages in sectoral structure (due to its specialization in dynamic sectors) with locational advantages (positive externalities associated to localization). Provinces in Category II have advantages due to its sectoral structure, since they are specialized in dynamic sectors, but their performance in the province is not adequate. Provinces in Category III have advantages due to its geographical location but not to its sectoral structure. Finally, provinces in Category IV face problems since neither their sectoral structure nor their locational characteristics contributes to employment growth.

\section{(Insert Table 1)}

Finally, to complete these results, we pay attention to Esteban (1972) who suggests a further decomposition of the regional share component that links localization advantages and specialization. He introduces the concept of homothetic employment, defined as the expected employment level in sector $i$ and province $r$ if such province would have had the national employment structure, in our notation: $\tilde{L}_{i}^{r}=L_{\bullet}^{r}\left[\frac{L_{i}^{\bullet}}{L_{\bullet}^{*}}\right]$. The concept of homothetic employment is related to specialization, measured by the location quotient ( $\left.\mathrm{LQ}_{\mathrm{i}, \mathrm{r}}\right)$, as:

$$
\text { if } \quad \mathrm{L}_{\mathrm{i}}^{\mathrm{r}}<\tilde{\mathrm{L}}_{\mathrm{i}}^{\mathrm{r}} \Rightarrow \quad \mathrm{LQ}_{\mathrm{i}, \mathrm{r}}=\frac{\frac{\mathrm{L}_{\mathrm{i}}^{\mathrm{r}}}{\mathrm{L} !}}{\frac{\mathrm{L}_{\mathrm{i}}^{\mathrm{r}}}{\mathrm{L} !}}<1
$$

Next, the Regional Share in (2) is decomposed into two additional terms, the so-called Net Regional Share (NRS) and a Distributional Effect (DE), as follows: 


$$
R S^{r}(t+m)=\sum_{i=1}^{S}\left[r_{i}^{r}-r_{i}^{\bullet}\right] L_{i}^{r}(t)=\underbrace{\sum_{i=1}^{S}\left[r_{i}^{r}-r_{i}^{\bullet}\right] \tilde{L}_{i}^{r}(t)}_{N R S}+\underbrace{\sum_{i=1}^{S}\left[r_{i}^{r}-r_{i}^{\bullet}\right]\left[L_{i}^{r}(t)-\tilde{L}_{i}^{r}(t)\right]}_{D E}
$$

For our purpose, we pay attention to the sign of the distributional effect, meaning that:

- A positive distributional effect corresponds to $\left.\begin{array}{c}r_{i}^{r}>r_{i}^{\bullet} \\ L_{i}^{r}>\tilde{L}_{i}^{r}\end{array}\right\}$ or $\left.\begin{array}{c}r_{i}^{r}<r_{i}^{\bullet} \\ L_{i}^{r}<\tilde{L}_{i}^{r}\end{array}\right\}$. In the first case the province $r$ is specialized in sectors for which the province has location advantages, while in the second case province $r$ is not specialized in sectors for which the province has not location advantages. In both cases, the specialization pattern is correct.

- A negative distributional effect occurs when $\left.\begin{array}{c}r_{i}^{r}>r_{i}^{\bullet} \\ L_{i}^{r}<\tilde{L}_{i}^{r}\end{array}\right\}$ or $\left.\begin{array}{c}r_{i}^{r}<r_{i}^{\bullet} \\ L_{i}^{r}>\tilde{L}_{i}^{r}\end{array}\right\}$. In the first case, province $r$ has location advantages for sectors in which the province is not specialized. In the second case, there are not location advantages for sectors in which the province is specialized. In both cases, we detect problems in the specialization pattern.

\section{2 “Engineering”/“Ecological” resilience}

We need a process in various stages in order to proxy the notion of "Engineering”/“Ecological”. First, it is necessary to estimate a model for the pre-crisis period. Second, estimation results are used to forecast the annual growth rate of total employment and the total employment level in the post crisis period, by provinces. The forecasts are treated as the counterfactual (or predicted) values in absence of the crisis. Finally, the comparison of forecasts and actual values will enable us to conclude on the resilient nature of Spanish provinces.

In order to estimate and forecast the provincial total employment growth, we adopt a spatial panel data approach since, as it is well-known, they allow for unobservable crosssectional and time effects, as well as to account for the spatial dependence between crosssectional units at any point in time. Spatial dependence implies that, due to spillover effects (e.g., commuters or trade flows), neighbouring regions may have similar economic performance. Hence, we expect to improve traditional panel data models by paying attention to geographical factors in the sample.

Prediction with spatial panel data models may be highly accurate, as shown by Baltagi and $\mathrm{Li}(2004,2006)$ in the case of per-capita cigarette and liquor consumption in the United 
States. Similarly, Longhi and Nijkamp (2007) obtained good predictions for the regional labour market in West German regions whereas Kholodilin et al. (2008) focused on GDP of German Länders. A comparison of different spatial panel data models is carried out by Baltagi et al. (2012). Furthermore, on the line of the present paper, Angulo and Trívez (2010) conclude that a dynamic spatial lag panel data model outperforms fifty non spatial seasonal ARIMA models, from a purely forecasting point of view.

We focus on the annual growth rate of total employment in all provinces $(r=1, \ldots, R)$ (seasonally differenced) which, from now on, will be denoted by the vector $y_{t}=\left[y_{1 t}, \ldots, y_{R t}\right]$, where $y_{r t}=\frac{L_{.}^{r}(t)-L_{.}^{r}(t-4)}{L_{.}^{r}(t-4)} 100$ with $L_{.}^{r}=\sum_{i=1}^{s} L_{i}^{r}$. Next, we compare three panel models which exploit the temporal and spatial dimensions of the data. All of them introduce provincial-specific intercepts, $\mu_{\mathrm{r}}(\mathrm{r}=1,2 \ldots, \mathrm{R})$, in order to account for the heterogeneity among spatial units.

The first model under consideration is the dynamic Fixed Effect (FE) panel data model, which is defined as follows:

$$
\left.\begin{array}{l}
\mathrm{y}_{\mathrm{rt}}=\beta_{1}+\beta_{2} \mathrm{Dq} 2_{\mathrm{t}}+\beta_{3} \mathrm{Dq} 3_{\mathrm{t}}+\beta_{4} \mathrm{Dq} 4_{\mathrm{t}}+\tau \mathrm{y}_{\mathrm{rt}-1}+\mu_{\mathrm{r}}+\eta_{\mathrm{rt}} \\
\eta_{\mathrm{rt}} \sim \mathrm{N}\left[0, \sigma_{\mathrm{\eta}}^{2}\right]
\end{array}\right\}
$$

where Dqj, with $\mathrm{j}=2,3$ and 4, is a seasonal dummy which has a value of 1 when evaluating growth for quarter $\mathrm{j}$ and 0 otherwise.

Model (5) considers the temporal dimension of data through the introduction of a lag of the dependent variable; this term takes into account the serial dependence between observations on each cross-sectional unit over time and it captures the inertia in the series. As largely analyzed in literature (see Hsiao, 2003; Sevestre and Trognon, 1996; Baltagi, 2005), Ordinary Least Square estimator applied to the demeaned equation ${ }^{4}$ is biased and inconsistent for $\mathrm{T}$ finite, regardless the number of cross-section in the sample ( $\mathrm{R}$ in our case). In fact, demeaning creates a correlation of order $(1 / \mathrm{T})$ between the demeaned term and the demeaned error term, known as the Nickel bias (Nickell, 1981). If $\mathrm{T}$ is fixed, alternative estimation methods have been suggested such as Anderson and Hsiao (1981), Arellano and Bond (1991),

\footnotetext{
${ }^{4}$ The demeaning equation is obtained by taking each variable in the regression equation in deviation from its average over time, for instance for the endogenous variable: $y_{r t}^{*}=y_{r t}-\frac{\sum_{t=1}^{T} y_{r t}}{T}$.
} 
Arellano and Bover (1995) or Blundell and Bond (1998). All of them propose to first difference the data to eliminate the cross-sectional fixed effects and then apply Generalized Method-of-Moments (GMM), using a set of appropriate instruments. Other proposals refer to the construction of bias corrected estimators for the dynamic panel data model, by analytically modifying the within estimator (Kiviet, 1995; Hahn and Kuersteiner, 2002; Bun and Carree, 2005). Finally, Hsiao et al. (2002) propose the use of Maximum Likelihood (ML) estimation based on the unconditional likelihood function of the model, concluding that ML estimator is asymptotically more efficient than the GMM. In this paper, Arellano and Bond (1991) procedure will be applied.

Second, we are going to use a model that pays attention to the spatial dimension of the data, by considering the cross-sectional dependence among the observations at each point in time; this is the spatial autoregressive (SAR) model of Cliff and Ord (1973). The static SAR specification includes the spatially lagged dependent variable as an additional regressor:

$$
\left.\begin{array}{l}
\mathrm{y}_{\mathrm{rt}}=\rho \sum_{\mathrm{j}=1}^{\mathrm{R}} \mathrm{w}_{\mathrm{rj}} \mathrm{y}_{\mathrm{jt}}+\beta_{1}+\beta_{2} \mathrm{Dq} 2_{\mathrm{t}}+\beta_{3} \mathrm{Dq} 3_{\mathrm{t}}+\beta_{4} \mathrm{Dq} 4_{\mathrm{t}}+\mu_{\mathrm{r}}+\eta_{\mathrm{rt}} \\
\eta_{\mathrm{rt}} \sim \mathrm{N}\left[0, \sigma_{\eta}^{2}\right]
\end{array}\right\}
$$

where $\mathrm{w}_{\mathrm{rj}}$ is the $(r, j)$ element of the spatial weight matrix $\mathrm{W}$. As is well known, this matrix is pre-specified, nonnegative, of order RxR and describes the arrangement of the cross-sectional units in the sample (Anselin, 1988, 2007). In the following, we refer this model as the Fixed Effect SAR model (FE-SAR).

Finally, to account simultaneously for the temporal and spatial dimensions of the data, we consider the so-called dynamic Fixed Effect SAR model, which read as follows:

$$
\left.\begin{array}{l}
y_{\mathrm{rt}}=\rho \sum_{\mathrm{j}=1}^{\mathrm{R}} \mathrm{w}_{\mathrm{rj}} \mathrm{y}_{\mathrm{jt}}+\beta_{1}+\beta_{2} \mathrm{Dq} 2_{\mathrm{t}}+\beta_{3} \mathrm{Dq} 3_{\mathrm{t}}+\beta_{4} \mathrm{Dq} 4_{\mathrm{t}}+\tau \mathrm{y}_{\mathrm{rt}-1}+\mu_{\mathrm{r}}+\eta_{\mathrm{rt}} \\
\eta_{\mathrm{rt}} \sim \mathrm{N}\left[0, \sigma_{\eta}^{2}\right]
\end{array}\right\}
$$

The estimation of model (7) is a bit more difficult than the previous two, given the strong endogeneity of the regressors. However, Yu et al. (2008) developed a bias corrected maximum likelihood algorithm with good properties.

Once models (5) to (7) have been estimated, we proceed to select the best specification using standard specification tests. As indicated before, the model chosen will be used to forecast the annual employment growth for the post-crisis period, which represents a proxy of 
annual total employment growth in Spanish provinces in absence of the economic crisis. Finally, we measure the effect of the crisis by comparing forecasted and actual values.

\section{Data}

The difference in resilience among Spanish regions is reinforced by the political decentralization process taken place in Spain. In 1978 Spain embarked on a rapid transition process from a highly centralized system in nearly every facet of public life (economy, politics, culture etc.) to a quasi-federal structure with 17 Autonomous Communities (NUTS2 units) or 52 provinces (NUTS3). The completion of the so-called 'Autonomic State' was achieved formally in 1983. Since then, the weight of the regions has increased systematically at the expense of the central State. The decentralisation process included 'own-source' revenues for sub-central governments and tax sharing agreements among the regions and the central government. Currently, regional governments are responsible for $40 \%$, approximately, of total public expenditure and for more than $50 \%$ of government employment. This autonomy facilitates the appearance of different policies among regions, which generate important regional disparities in terms of sectoral specialization, employment, productivity, etc.

We use data on total employment for each of the fifty ${ }^{5}$ Spanish provinces, obtained on a quarterly basis for the period 2002:1 to 2015:4. The series are taken from the Encuesta de Población Activa (EPA), published by the Instituto Nacional de Estadística (INE). As said before, we will pay attention to employment distributions among the four main sectors (agriculture, industry, construction and services) since resilience to the crisis may differ due to the different sectoral employment structure.

Figure 2 presents the evolution and sectoral disaggregation of Spanish employment along the analysed period. Figure 2a shows a strong decrease in employment starting in $2008: 2^{6}$ due to the global economic crisis; however, its impact is not equal for the four sectors. Figure $2 \mathrm{~b}$ shows that the economic crisis has provoked a strong decrease in the

\footnotetext{
${ }^{5}$ We have excluded the Spanish autonomous cities of Ceuta and Melilla.

${ }^{6}$ Such a breakpoint has also been confirmed through the calculation of successive F-Chow tests applied to the proposed models for all possible time periods.
} 
weight of construction in favour of the service sector, while agriculture and industrial shares are less affected.

\section{(Insert Figure 2)}

To asset provinces specialization pattern, the location quotient for province $r$ in sector $i$ in period $t$, has been calculated as appears in expression (3). These coefficients allows us to declare a province $r$ as specialized in sector $i$ for that period $t$ if the corresponding $L_{\mathrm{i}, \mathrm{r}}(\mathrm{t})$ is higher than 1.

For the purpose of our study, we are interested in comparing the provincial specialization patterns in two different periods (pre- and post- crisis) and for the four sectors. A general overview of provincial specialization patterns appears in Figure 3, which depicts the relative frequency of specialization by provinces and periods; darker colours mean that the corresponding provinces appears as specialized in the respective sector at least half of the quarters.

\section{(Insert Figure 3)}

The specialization patterns in the pre- and post- crisis periods are quite similar for all the sectors except construction ${ }^{7}$. Furthermore, the maps show that, in general, the Northern provinces are specialized in industry; the Southern and Western provinces are specialized in agriculture; and finally, the coastal (such as Canary Islands, Málaga, Cádiz, Granada and Valencia) and central regions (such as Madrid, Salamanca or Zaragoza) tend to be specialized in the service sector.

\section{Results}

\subsection{Adaptative resilience}

As explained before, we have solved two shift-share decompositions in order to analyze employment growth before and after the shock. Hence, since the Spanish crisis has been already determined in the period 2008:2, we decompose the employment growth between industrial mix and regional share for the fifty Spanish provinces between 2002:1 and 2008:2,

\footnotetext{
${ }^{7}$ In fact, the correlation coefficient among periods for each sector is the following: i) agriculture: 0.9644; ii) industry: 0.8984; iii) construction: 0.4307 ; and iv) services: 0.9561 .
} 
on one hand, and between 2008:2 and 2015:4, on the other. Results are shown in Figure 4, and they are also mapped in Appendix (Figure A1).

(Insert Figures 4 and A1)

For our purposes, in relation to this notion of resilience, the most interesting part of the two figures refers to the similarities and dissimilarities between them. We summarize the changes according the following classification: (i) provinces that remain stable in categories I, II or III among both periods; (ii) provinces that improve in both components, Industrial Mix (IM) and Regional Share (RS); (iii) provinces that improve in only one component, IM or RS; and finally (iv) the remaining cases will be classified as low-resilient provinces. The results obtained are shown in Figure 5.

\section{(Insert Figure 5)}

In this Figure we identify a group of high resilient provinces among which Málaga and Granada appear in the shift-share Category I in both sub periods. There is also a cluster of provinces of group (i) following the Aragonese axe in the Ebro valley, in the North-East of the peninsula, composed by Araba, Zaragoza, Huesca, Teruel, Cuenca and Lleida. The provinces of group (ii), which have improved both shift-share components are concentrated in the North, including cases in the Autonomous Community of Galicia (A Coruña, Lugo) and Basque Country (Gipuzkoa), also Palencia. Provinces in group (iii) have improved at least one the components, and they are very dispersed over the peninsula with cases in the North (Asturias, Leon, Navarra), in the center (such as Salamanca, Badajoz or Madrid) and in the South (Canary Islands or Almería). The remaining provinces should be classified as lowresilient, since they have worsened their situation after the crisis. Among them, we can find Southern provinces such as Sevilla, Cádiz, Huelva or Cáceres together with most provinces along the Mediterranean axe such as Girona, Barcelona, Tarragona, Castellón, Valencia, Murcia and Baleares.

Figures 6 shows the decomposition of the Regional Share into the Net Regional Share (NRS) and the distributional effect (DE) for the fifty Spanish provinces in pre-crisis (between 2002:1 and 2008:2) and post-crisis (2008:2 to 2015:4) periods. In addition, the sign of the distributional effect for both sub-periods is mapped in the Figure A2 in the Appendix.

(Insert Figures 6 and A2)

As before, changes in the sign of the Distributional Effect (DE) between the two periods are represented in Figure 7, which allows us to distinguish three groups of provinces: 
(a) provinces that have improved their DE sign (in the sense that the sign changes from negative to positive); (b) provinces that have not changed its sign between periods (stable DE sign) and finally, (c) provinces that have worsened their DE sign (from positive to negative).

\section{(Insert Figure 7)}

In general, we can conclude that Spanish provinces have maintained or improved their specialization profile in the post-crisis period. The worst situation corresponds to the Eastern and Northern provinces such as Girona, Tarragona, León, Ourense, Cantabria, Gipuzkoa and Navarra, who change the sign from positive to negative.

\section{2 “Engineering”/“Ecological” resilience}

Results for the estimation of the three proposed panel data models are gathered in Table 2. Regarding the $\mathrm{W}$ matrix, among different alternatives (always based on measures of geographical distance), we have chosen the four-nearest neighbor criteria because of its simplicity, its balance between null and non-null elements and its adequacy in terms of estimated models ${ }^{8}$. As can be seen in the Table, the inertia in employment growth and the neighborhood effect are highly significant. Moreover, significance tests and measures of goodness of fit indicate that the Dynamic Fixed Effect Spatial Autoregressive (Dynamic FE$S A R$ ) is the best model for our case. Furthermore, annual employment growth does not significantly differ among seasons.

\section{(Insert Table 2)}

To cope with our objective, and using this model, we forecast the annual employment growth for the period 2008:3-2015:4, which represents a proxy of annual total employment growth in Spanish provinces in absence of the economic crisis. The differences between the respective forecast and the actual growth are positive for all regions and periods representing, as said, the impact of the crisis on regional employment. Hence, as regards resilience, this means that any Spanish province has been resilient to the crisis.

(Insert Figure 8)

\footnotetext{
${ }^{8}$ Several studies have analyzed the consequences of sparser/denser matrix (see for instance Smith, 1999). Moreover, our results are consistent with other W matrices specified on the basis of the inverse of the distance between centroids in the provinces or the inverse of the square of such distances. Matrices based on the contiguity criteria have been discarded since we assume that (following Zeilstra and Elhorst, 2014), interaction in employment markets is determined, mainly, by distance.
} 
From now on, we will refer to these positive differences as "growth drop". A summary of them appears in Figure 8. Figure 8a depicts a map of the provincial average "growth drops" after the crisis, which shows that the "growth drops" are not homogeneously distributed among all the Spanish provinces. In fact, a Wald test of homogeneity among the fifty provinces takes a value of 146.18 , which is higher than the critical value of a $\chi^{2}(49)$ at the $5 \%$ level of significance. Differences among the provinces can be measured by comparing each provincial average "growth drop" with the national average (equal to 5.259\%). Results appears in Figure $8 \mathrm{~b}$ and show that the provinces with performance better than the average are A Coruña, Lugo, Araba, Bizkaia, Salamanca, Palencia, Segovia, Soria and Canary Islands.

\section{3 “Adaptative” versus "Engeniering"/“Ecological” resilience uses}

As explained before, one of the purposes of this study is connected to the relation between "Adaptative” and the other two notions of resilience. We envisage three procedures to carry out this analysis.

First, the estimated "growth drop" for each province will be regressed on the information on provincial specialization. Before doing the regression, we define six dummy variables $D b c c_{j}$ and $D p c c_{j}$, (j=1,2 and 3), with a value of 1 for all provinces that are classified as category j according to Industry Mix and Regional Shift share for the pre-crisis period (2002:1-2008:2) and post-crisis period (2008:2-2015:4), respectively (note that the reference category is the fourth). Similarly, Dbcpde and Dpcpde are binary variables taking a value of 1 if a province presents a positive distributional effect (right specialization), and 0 otherwise, in the pre- or post-crisis period. A trend variable is also included in the equation to account for a global national trend along the post-crisis period. Three models, A, B and C, are estimated with different combination of previous dummy variables: only post-crisis variables (Model A), only before-crisis variables (Model B) and, finally, both types of variables (Model C). Estimation results appear in Table 3.

\section{(Insert Table 3)}

As shown in this Table, provincial "growth drops” have significantly decreased across time. Regarding sectoral composition effect, results indicate that provinces with advantages in sectoral structure and localization (Category I) or those with advantage in location (Category III) in the post-crisis period exhibit a significantly lower "growth drop". The opposite takes place in reference to the pre-crisis period: regions classified as strong, looking at their sectoral 
composition, suffered the largest "growth drop". These results can be interpreted in the sense that the crisis changed dramatically the leading sectors of the Spanish economy. Finally, Table 3 shows that the right/wrong specialization pattern does not have a significant effect in "growth drops".

The second block of results refers to the relationship between the "Adaptative" notion (related to the Industrial Mix, IM and/or Regional Share, RS, together with the improvement in specialization pattern) and the "drop growth" results (measured in terms of a dummy variable that takes the value of one for provinces with a lower "drop growth" than the national average). Results for the estimated probit model are shown in Table 4, together with some diagnostics which enable us to validate our estimations.

\section{(Insert Table 4)}

As expected, results in Table 4 show that provinces that improve the two components, IM and RS (according to the "Adaptative” perspective) are more likely to present a behavior better than the national average. In fact, for this group, the probability of presenting a better behavior is 0.536 higher than for the others. Furthermore, provinces that only improve one of the two components also present a significantly higher probability of behaving better than the others but, in this case, the marginal effect is lower (0.236). Finally, changes in the specialization pattern does not have a significant influence on probability.

The third procedure considers the relation between "growth drops" and sector specialization. To cope with this objective, we estimate a probit model to measure the influence of sector specialization in the pre- and post- crisis periods on the probability of presenting better behavior than the national average (or a significant lower "growth drop"). Results appear in Table 5.

\section{(Insert Table 5)}

In first place, according to the significance tests in the Table, we can conclude that "growth drops" are significantly related to pre-crisis provincial specialization. The probability of having better performance than the national average increases for those provinces specialized in the service sector in the pre-crisis period. As expected, the worse behavior is for provinces specialized in the construction sector also in the pre-crisis period. Although not significant, specialization in agriculture and industry is also positively related to the probability of presenting better behavior than the average. These results are in line with Cuadrado-Roura and Maroto (2016), who also concluded that the most resilient regions are 
those previously specialized in some advanced market services together with dynamic and productive industries.

\section{Conclusions}

There is wide consensus in the applied literature on the negative effects of the recent global downturn. However, its impact differs substantially between countries, and even between different regions in the same country; the same can be said in relation to the way the territories overcame the crisis. Consequently, many economists have focused on identifying the factors that minimise the impact of the crisis. This line of research is closely related with the concept of resilience of a territory. Our objective is to evaluate the resilience of Spanish provinces to the recent global downturn.

According to the literature, a region can be classified as resilient, in terms of the socalled "Adaptative" resilience, if it has the capacity to reconfigure, that is, to adapt its structure (firms, industries, technologies and institutions) so as to maintain an acceptable growth path in employment, output or wealth over time. In this paper, we have approached this issue through a traditional shift-share analysis applied both, to the pre-and post-crisis periods. Under this approach, a region is resilient if, after the economic crisis, it has maintained, or even improved, its situation according to sectoral structure and locational advantages. Results show that the most resilient Spanish provinces are Málaga, A Coruña, Lugo, Gipuzkoa, Palencia, as well as some others in the Western part of Spain, in the North or in the centre like, Madrid.

Other resilience notions, named as “Engineering” and "Ecological” resilience, refer to differences in growth and level of total employment between both periods. According to an "Engineering” approach, a province is high resilient if its actual employment growth (and level of employment) is statistically the same as the forecasted one within a relatively short period of time. According to the "Ecological” notion, a province is high resilient if its postshock employment growth rate is higher or equal than the pre-shock growth rate within a relatively short period of time. Furthermore, in the case of equality, the employment level must also be higher than the predicted one in absent of the crisis. If some of the previous requirements are not accomplished, the region will be classified as low resilient. To evaluate this issue, in this paper we have used forecasts from a spatial panel data model to evaluate provincial resilience to the crisis. Results have shown that all Spanish provinces have been 
low resilient to the crisis. However, the provinces that exhibited a better behavior than the national average are A Coruña, Lugo, Araba, Bizkaia, Salamanca, Palencia, Segovia, Soria and Canary Islands.

Next, the paper has analysed the relationship between the different resilience notions, for the case of Spain. We have found that provinces with sectoral structure and locational advantages (appear in the shift-share Category I) or those with advantage in location (Category III) in the post-crisis period, have a significantly lower "growth drop" (according to the "Engineering" and "Ecological" resilience measures). The opposite takes place in reference to the pre-crisis period, since the largest "growth drop" has been suffered by regions that appeared to be in a stronger situation in the pre-crisis period. Moreover, those provinces improving the two shift-share components, IM and RS (according to the "Adaptative" perspective), are more likely to present a behavior better than the national average. Moreover, the probability of presenting a better behavior (lower "growth drop" than the national average) increases for those regions specialized in the service sector before the crisis. As expected, the worse behavior corresponds to those regions specialized in the construction sector.

To conclude, let us remark from our results that sectoral and locational advantages are very important to mitigate the negative effects of a crisis. Furthermore, also in the Spanish specific case, those regions specialized in the service sector (also in industry, to a lesser extend) suffered the crisis in a smoother way. Consequently, in a decentralized economy, such as the current Spanish case, it is important to develop a strong and persistent policy supporting the most dynamic sectors of the economy. Only in this case, provinces will suffer a global economic crisis, like that that hit the World economy in 2008, in a smoothest way. Of course, this will not prevent from the crisis, but surely will reduce its impact on the territory.

Finally, let us conclude that although we have found certain relationship between the different resilience notions, the conclusions depend to a great extent on the techniques for measuring them. The selection of the most adequate technique is a matter of choice, but some cautiousness must be taken when comparing different approaches. 


\section{References}

Anderson TW, Hsiao C (1981) Estimation of dynamic models with error components. Journal of the American Statistical Association 76: 598-606

Angulo A, Trívez FJ (2010) The impact of spatial elements on the forecasting of Spanish labour series. Journal of Geographical Systems 12: 155-174

Anselin L (1988) Spatial econometrics: methods and models. Kluwer, Dordrecht

Anselin L (2007) Spatial Econometrics. In: Mills TC, Patterson K (eds) Handbook of econometrics, Vol. 1. Palgrave, Basingstoke, pp 901-969

Arellano M, Bond S (1991) Some tests of specification for panel data: monte carlo evidence and application to employment equations. Review of Economic Studies 58: 277-297

Arellano M, Bover O (1995) Another look at the instrumental-variable estimation of error-components models. Journal of Econometrics 68, 29-51

Augustine N, Wolman H, Wial H, McMillen M (2013) Regional Economic Capacity, Economic Shocks and Economic Resilience, MacArthur Foundation Network on Building Resilient Regions, Working Paper May.

Baltagi BH (2005) Econometric Analysis of Panel Data (3 ${ }^{\text {rd }}$ Edition). Wiley, Chichester

Baltagi BH, Li D (2004) Prediction in the panel data model with spatial correlation. In: Anselin L, Florax RJGM, Rey S (Eds) Advanced in spatial econometrics: methodology, tools and application. Springer-Verlag, Heidelberg (Germany): 283-295

Baltagi BH, Li D (2006) Prediction in the panel data model with spatial correlation: the case of liquor. Spatial Economic Analysis 1(2): 175-185

Baltagi BH, Bresson G, Pirotte A (2012) Forecasting with spatial panel data. Computational Statistics and Data Analysis 56: 3381-3397

Blundell R, Bond S (1998) Initial conditions and moment restrictions in dynamic panel data models. Journal of Econometrics 87: 115-143

Bun M, Carree M (2005) Bias-corrected estimation in dynamic panel data models. Journal of Business \& Economic Statistics 3 (2): 200-210(11)

Cliff AD, Ord JK (1973) Spatial Autocorrelation. Pion Ltd., London.

Cuadrado-Roura JR, Maroto A (2016) Unbalanced regional resilience to the economic crisis in Spain: a tale of specialisation and productivity. Cambridge Journal of Regions, Economy and Society 9(1): 153-178

Doran J, Fingelton B (2013) US Metropolitan Area Resilience: Insights from Dynamic Spatial Panel Estimation, Paper presented at the Annual Conference of the Regional Science Association International (British and Irish Section),University of Cambridge, August 22

Esteban J (1972) A reinterpretation of shift-share analysis. Regional and Urban Economics 2: 249261.

Evans R, Karecha J (2013) Staying on Top: Why is Munich so Resilient and Successful? European Planning Studies, DOI:10.1080/09654313.2013.778958

Fingleton B, Garretsen, H, Martin R (2012) Recessionary Shocks and Regional Employment, Journal of Regional Science 52 (1): 109-133

Fingleton B, Palombi S (2013) Spatial panel data estimation, counterfactual predictions and local economic resilience among British towns in the Victorian era, Regional Science and Urban Economics 43: 649-660 
Foster KA (2007) A case study approach to understanding regional resilience. Working Paper 200708, Institute of Urban and Regional Development, Berkeley

Hahn J, Kuersteiner G (2002) Asymptotically unbiased inference for a dynamic panel model with fixed effects when both $\mathrm{n}$ and T are Large. Econometrica 70(4): 1639-1657

Hill E, Wial H, Wolman H (2008) Exploring regional economic resilience. Working paper 2008 (4). Institute Urban and Regional Development, UC Berkeley

Holling CS (1973) Resilience and stability of ecological systems. Annual Review of Ecology and Systematics 4: 1-23

Holling CS (1996) Engineering resilience versus ecological resilience. In P. Schulze (ed.).Engineering within Ecological Constraints, pp. 31-44. Washington, DC: National Academy Press

Holling CS (2001) Understanding the complexity of economic, ecological and social systems. Ecosystems 4: 390-405

Hsiao C (2003) Analysis of panel data ( $2^{\text {nd }}$ Edition). Cambridge University Press, Cambridge

Hsiao C, Pesaran MH, Tahmiscioglu AK (2002) Maximum Likelihood Estimation of Fixed Effects Dynamic Panel Data Models Covering Short Time Periods. Journal of Econometrics 109: 107-150

Instituto Nacional de Estadística, INE (several years). Encuesta de población activa. Madrid

Kholodilin KA, Siliverstovs B, Kooths S (2008) A dynamic panel data approach to the forecasting of the GDP of German Länder. Spatial Economic Analysis 3(2): 195-207

Kiviet J (1995) On bias, inconsistency, and efficiency of various estimators in dynamic panel data models. Journal of Econometrics 68: 81-126

Longhi S, Nijkamp P (2007) Forecasting regional labor market developments under spatial heterogeneity and spatial correlation. International Regional Science Review 30: 100-119

Martin R (2012) Regional economic resilience, hysteresis and recessionary shocks. Journal of Economic Geography 12: 1-32

Martin RL, Sunley P (2015) On the notion of regional economic resilience: conceptualization and explanation. Journal of Economic Geography 15: 1-42

McGlade J, Murray R, Baldwin J, Ridgway K, Winder B (2006) Industrial resilience and decline: a coevolutionary framework. In E. Garnsey, J. McGlade (eds) Complexity and Co-Evolution: Continuity and Change in Socio-economic Systems, pp. 147-176. Cheltenham: Edward Elgar.

Modica M, Reggiani A (2015) Spatial economic resilience: overview and perspectives. Networks and Spatial Economics 15: 211-233.

Nickell SJ (1981) Biases in dynamic models with fixed effects. Econometrica 49:1417-1426

Romer R (2001) Advanced Macroeconomics. New York: McGraw Hill

Sevestre P, Trognon A (1996) Dynamic linear models. In: Mátyás L, Sevestre P The econometrics of panel data, 2nd revised edition. Kluwer, Dordrecht (The Netherlands)

Smith T (2009) Estimation Bias in Spatial Models with Strongly Connected Weight Matrices. Geographical Analysis 41: 307-332.

Walker B, Gunderson L, Kinzig A, Folke C, Carpenter S, Schultz L (2006) A handful of heuristics and some propositions for understanding resilience in socio-ecological systems. Ecology and Society, 11. Available online at: http://www.ecologyand society.org/vol11/iss1/art13/ [Accessed 1 December 2010]

Zeilstra J, Elhorst P (2014) Integrated Analysis of Regional and National Unemployment Differentials in the European Union. Regional Studies 48: 1739-1755 
Yu J, de Jong R, and Lee LF (2008) Quasi-maximum likelihood estimators for spatial dynamic panel data with fixed effects when both $\mathrm{N}$ and $\mathrm{T}$ are large. Journal of Econometrics 146:118-134 
Table 1. Region classification according to overall Industrial and Regional Share

\begin{tabular}{|c|c|c|}
\hline Category & Industrial Mix & Regional Share \\
\hline I & + & + \\
\hline II & + & - \\
\hline III & - & + \\
\hline IV & - & - \\
\hline
\end{tabular}

Table 2. Results obtained for the panel data model specifications ${ }^{\text {(a), (b), (c) }}$

\begin{tabular}{|c|c|c|c|}
\hline & $\begin{array}{l}\text { Dynamic } \\
\text { FE }\end{array}$ & $\begin{array}{c}\text { Static } \\
\text { FE- SAR }\end{array}$ & $\begin{array}{l}\text { Dynamic } \\
\text { FE- SAR }\end{array}$ \\
\hline Constant & $\begin{array}{c}1.316 * * * \\
(0.046)\end{array}$ & & \\
\hline$\tau$ & $\begin{array}{c}0.622 * * * \\
(0.039)\end{array}$ & & $\begin{array}{c}0.553 * * * \\
(0.027)\end{array}$ \\
\hline Dq2 & $\begin{array}{c}-0.169 * * * \\
(0.039)\end{array}$ & $\begin{array}{l}-0.198 \\
(0.253)\end{array}$ & $\begin{array}{l}-0.129 \\
(0.228)\end{array}$ \\
\hline Dq3 & $\begin{array}{c}0.297 * * * \\
(0.041)\end{array}$ & $\begin{array}{c}0.301 \\
(0.266)\end{array}$ & $\begin{array}{c}0.232 \\
(0.238)\end{array}$ \\
\hline $\mathrm{Dq} 4$ & $\begin{array}{l}0.066^{* *} \\
(0.066)\end{array}$ & $\begin{array}{c}0.187 \\
(0.266)\end{array}$ & $\begin{array}{c}0.066 \\
(0.238)\end{array}$ \\
\hline$\rho$ & & $\begin{array}{c}0.266^{* * *} \\
(0.038)\end{array}$ & $\begin{array}{c}0.212^{* * *} \\
(0.036)\end{array}$ \\
\hline $\mathrm{R}^{2}$ & 0.374 & 0.138 & 0.398 \\
\hline Log Ver. & & -2814.25 & -2522.68 \\
\hline $\begin{array}{l}\text { Number of } \\
\text { observations }\end{array}$ & 1000 & 1100 & 1050 \\
\hline \multicolumn{4}{|c|}{ Tests for serial autocorrelation ${ }^{(b)}$} \\
\hline $\begin{array}{l}\mathrm{H}_{0}: \text { No } \\
\text { autocorrelation of } \\
\text { order } 1\end{array}$ & $-4.218^{* * *}$ & 0.542 & 0.005 \\
\hline $\begin{array}{l}\mathrm{H}_{0}: \text { No } \\
\text { autocorrelation of } \\
\text { order } 2\end{array}$ & 0.318 & 0.280 & 0.064 \\
\hline \multicolumn{4}{|c|}{ Sargan test of overidentifying restrictions } \\
\hline $\begin{array}{l}\mathrm{H}_{0} \text { : overidentifying } \\
\text { restrictions are valid }\end{array}$ & 47.23 & & \\
\hline
\end{tabular}

(a) Robust standard deviation in parenthesis.

(b) * means significant al 10\%; ** means significant al 5\%; *** means significant al $1 \%$.

(c) Arellano-Bond tests in the case of dynamic FE model and Breusch-Godfrey test in the cases of FE-SAR models. 
Table 3. Relationship between "growth drop" and shift-share analyses ${ }^{(a),(b)}$

\begin{tabular}{|l|c|c|c|}
\hline & Model A & Model B & Model C \\
\hline Constant & $47.96^{* * *}$ & $46.23 * * *$ & $47.09 * * *$ \\
& $(2.56)$ & $(2.577)$ & $(2.57)$ \\
\hline Trend & $-0.201^{* * *}$ & $-0.201 * * *$ & $-0.201 * * *$ \\
& $(0.012)$ & $(0.012)$ & $(0.012)$ \\
\hline Dbcc ${ }_{1}$ & & $1.406^{* * *}$ & $1.383 * * *$ \\
& & $(0.381)$ & $(0.381)$ \\
\hline Dbcc $_{2}$ & & $-0.577 *$ & -0.111 \\
& & $(0.326)$ & $(0.356)$ \\
\hline Dbcc $_{3}$ & & $1.511^{* * *}$ & $1.086 * * *$ \\
& & $(0.258)$ & $(0.294)$ \\
\hline Dbcpde $^{*}$ & $0.429^{* *}$ & 0.156 \\
& & $(0.2184)$ & $(0.227)$ \\
\hline Dpcc $_{1}$ & & & $-1.691 * * *$ \\
& & & $(0.379)$ \\
\hline Dpcc $_{2}$ & $-2.394 * * *$ & -0.385 \\
& $(0.285)$ & & $(0.362)$ \\
\hline Dpcc $_{3}$ & -0.483 & & $-0.824 * * *$ \\
& $(0.321)$ & & $-0.276)$ \\
\hline Dpcpde $^{*}$ & $-0.794 * * *$ & $(0.224)$ \\
\hline
\end{tabular}

(a) Robust standard deviation in parenthesis.

(b) * means significant al 10\%; ** means significant al 5\%; *** means significant al $1 \%$. 
Table 4. "Ecological” versus “Adaptative” resilience. Relationship between changes (between pre- and post- crisis period) in regional classification and Distributional Effect (DE) sign and the fact of presenting better behavior than the national average ${ }^{(a),(b)}$

\begin{tabular}{|c|c|c|}
\hline & $\begin{array}{c}\text { ESTIMATED } \\
\text { PARAMETERS }\end{array}$ & $\begin{array}{l}\text { MARGINAL EFFECT } \\
\text { (at mean) }\end{array}$ \\
\hline \multicolumn{3}{|c|}{ From changes between regional classification among pre- and post- crisis period $^{(\mathrm{c})}$} \\
\hline Stable in Cat. I, II or III & $\begin{array}{c}0.583 \\
(0.674)\end{array}$ & $\begin{array}{c}0.122 \\
(0.140)\end{array}$ \\
\hline Improving in both, IM and RS & $\begin{array}{l}2.569 * * * \\
(0.717)\end{array}$ & $\begin{array}{c}0.536 * * * \\
(0.182)\end{array}$ \\
\hline Improving in one, IM or RS & $\begin{array}{l}1.131^{*} \\
(0.586)\end{array}$ & $\begin{array}{l}0.236^{*} \\
(0.123)\end{array}$ \\
\hline \multicolumn{3}{|c|}{ From changes in DE sign among pre- and post- crisis period $^{(\mathrm{d})}$} \\
\hline Stable in sign & $\begin{array}{c}0.468 \\
(0.819)\end{array}$ & $\begin{array}{c}0.098 \\
(0.164)\end{array}$ \\
\hline Improving in DE sign & $\begin{array}{c}0.904 \\
(0.869)\end{array}$ & $\begin{array}{c}0.189 \\
(0.176)\end{array}$ \\
\hline Constant & $\begin{array}{c}-2.278^{* * * *} \\
(0.792)\end{array}$ & \\
\hline \multicolumn{3}{|c|}{ SPECIFICATION TESTS } \\
\hline \multicolumn{3}{|l|}{$\mathrm{H}_{0}$ : Right specification } \\
\hline LM test & 0.37 & \\
\hline Hosmer-Lemeshow (4) & 1.45 & \\
\hline Hosmer-Lemeshow (10) & 3.04 & \\
\hline $\begin{array}{l}\mathrm{H}_{0}: \text { No differences among different } \\
\text { regional categories }\end{array}$ & $13.95 * * *$ & \\
\hline $\begin{array}{l}\mathrm{H}_{0}: \text { No differences among difference } \\
\text { distributional sign }\end{array}$ & 1.30 & \\
\hline
\end{tabular}

(a) Robust standard deviation in parenthesis.

(b) * means significant al 10\%; ** means significant al 5\%; *** means significant al $1 \%$.

(c) The reference category is the non-resilience region group.

(d) The reference category is the region group that are worsening in DE sign (from positive in 2002:12008:2 to negative in 2008:2-2015:4). 
Table 5. "Ecological” versus “Adaptative" resilience. Relationship between regional specialization (before and post crisis) and the fact of presenting better behavior than the national average $^{(a),(b)}$

\begin{tabular}{|c|c|c|c|c|}
\hline & \multicolumn{2}{|c|}{$\begin{array}{c}\text { For those regions } \\
\text { specialized before crisis in }\end{array}$} & \multicolumn{2}{|c|}{$\begin{array}{c}\text { For those regions } \\
\text { specialized after crisis in }\end{array}$} \\
\hline & Parameters & $\begin{array}{c}\text { Marginal } \\
\text { Effects }\end{array}$ & Parameters & $\begin{array}{l}\text { Marginal } \\
\text { Effects }\end{array}$ \\
\hline Agriculture & $\begin{array}{c}0.678 \\
(1.880)\end{array}$ & $\begin{array}{c}0.141 \\
(0.398)\end{array}$ & $\begin{array}{c}-0.318 \\
(1.806)\end{array}$ & $\begin{array}{l}-0.066 \\
(0.378)\end{array}$ \\
\hline Industry & $\begin{array}{c}0.534 \\
(1.154)\end{array}$ & $\begin{array}{c}0.111 \\
(0.237)\end{array}$ & $\begin{array}{l}-1.434 \\
(1.031)\end{array}$ & $\begin{array}{l}-0.298 \\
(0.212)\end{array}$ \\
\hline Construction & $\begin{array}{c}-1.506 * * \\
(0.761) \\
\end{array}$ & $\begin{array}{c}-0.314^{* *} \\
(0.161) \\
\end{array}$ & $\begin{array}{l}1.088 \\
(0.879) \\
\end{array}$ & $\begin{array}{c}0.226 \\
(0.178) \\
\end{array}$ \\
\hline Services & $\begin{array}{l}3.037 * * \\
(1.247)\end{array}$ & $\begin{array}{l}0.631 * * \\
(0.288)\end{array}$ & $\begin{array}{l}-2.289 \\
(1.456)\end{array}$ & $\begin{array}{c}-0.476 \\
(0.315)\end{array}$ \\
\hline \multicolumn{5}{|l|}{ Hypothesis tests: } \\
\hline \multicolumn{5}{|l|}{$\mathrm{H}_{0}$ : Right specification } \\
\hline LM test & 0.21 & & & \\
\hline Hosmer-Lemeshow (4) & 1.30 & & & \\
\hline Hosmer-Lemeshow (10) & 7.49 & & & \\
\hline $\begin{array}{l}\mathrm{H}_{0}: \text { No differences among } \\
\text { specializations before crisis }\end{array}$ & $13.84 * * *$ & & & \\
\hline $\begin{array}{l}\mathrm{H}_{0} \text { : No differences among } \\
\text { specializations after crisis }\end{array}$ & & & 4.74 & \\
\hline
\end{tabular}

(a) Robust standard deviation in parenthesis.

(b) * means significant al 10\%; ** means significant al 5\%; *** means significant al $1 \%$. 
Figure 1. "Engineering” versus “Ecological” resilience

“Engineering” Resilience or regional economic "rebound”

Figure 1a

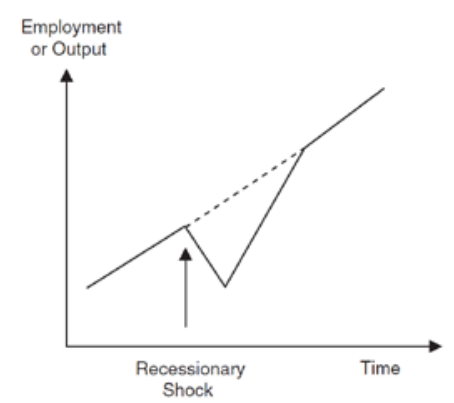

Low "Ecological” resilience or negative regional economic "hysteresis"

Figure 1b

Employment

Or Output

$\uparrow$

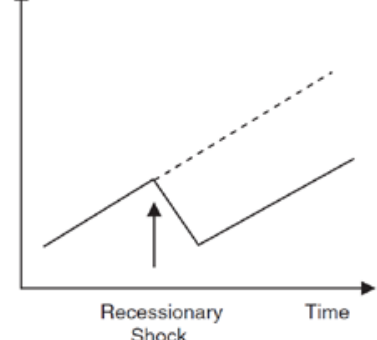

Shock
Figure 1c

Employmen

Or Output

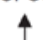

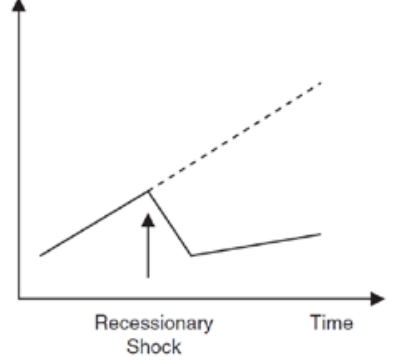

High "Ecological” resilience or positive regional economic "hysteresis"

Figure 1d

Source: Martin R (2012). 
Figure 2. Evolution of national employment

Figure 2a. Total and sectoral Spanish workers (miles of workers)

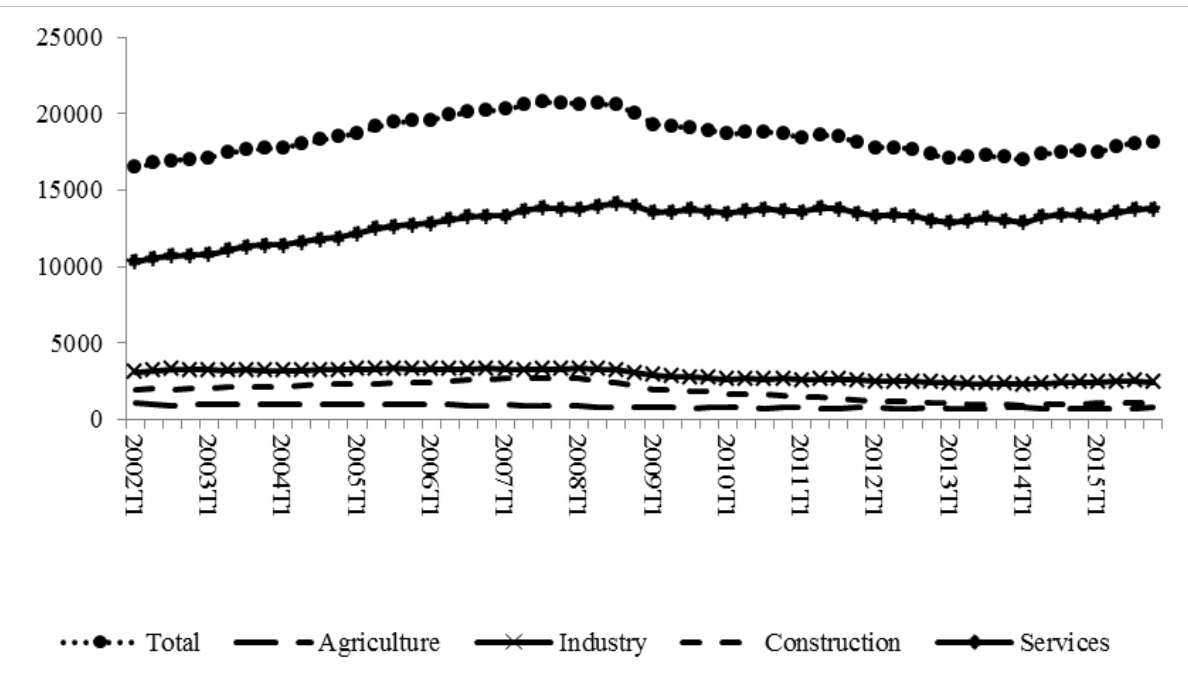

Figure 2b: Sectoral share over total Spanish employment

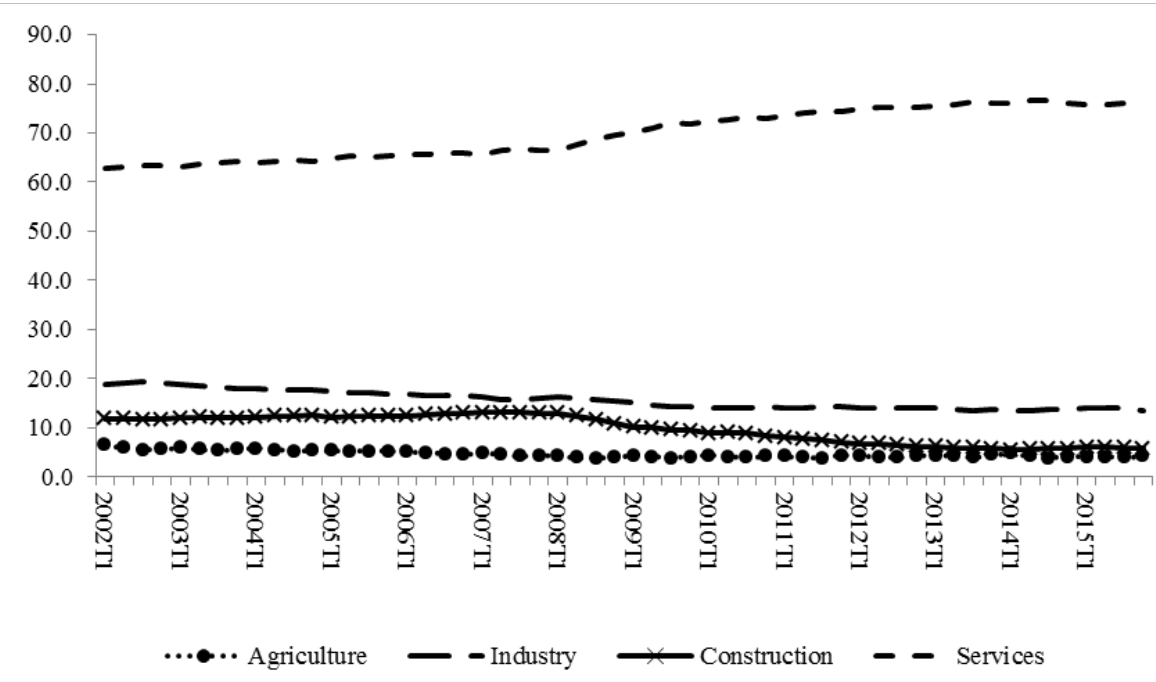


Figure 3. Frequencies of specialization pattern by sectors and periods
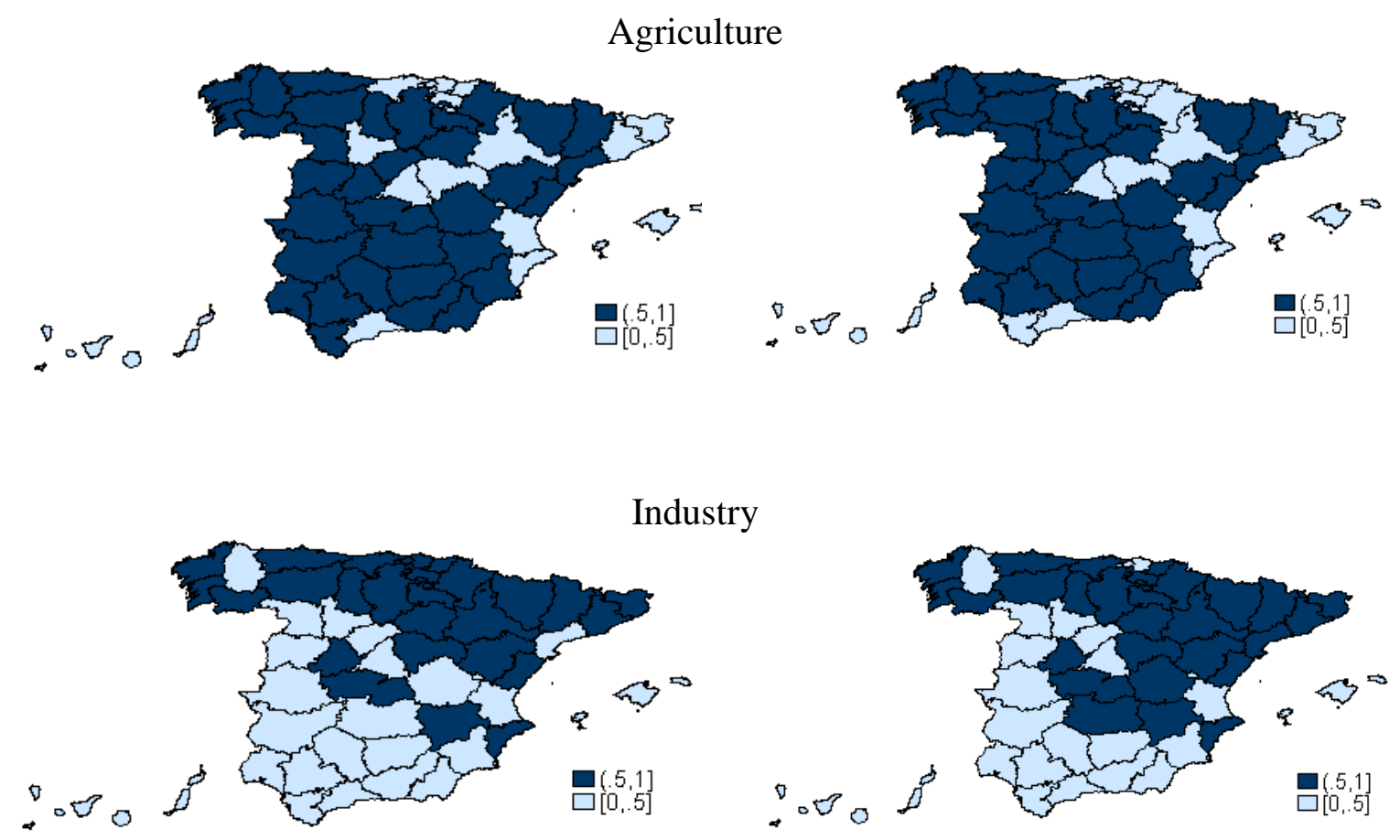

Construction

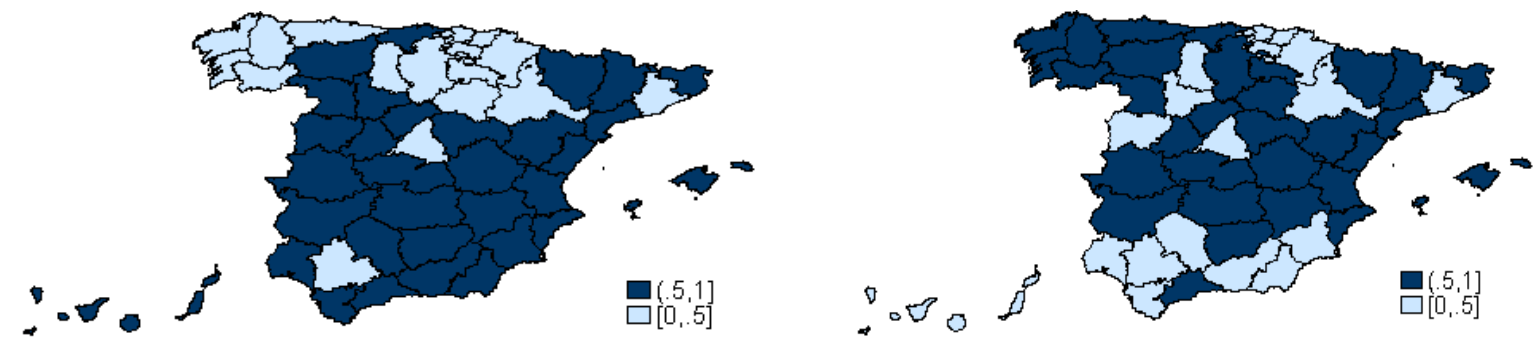

Services

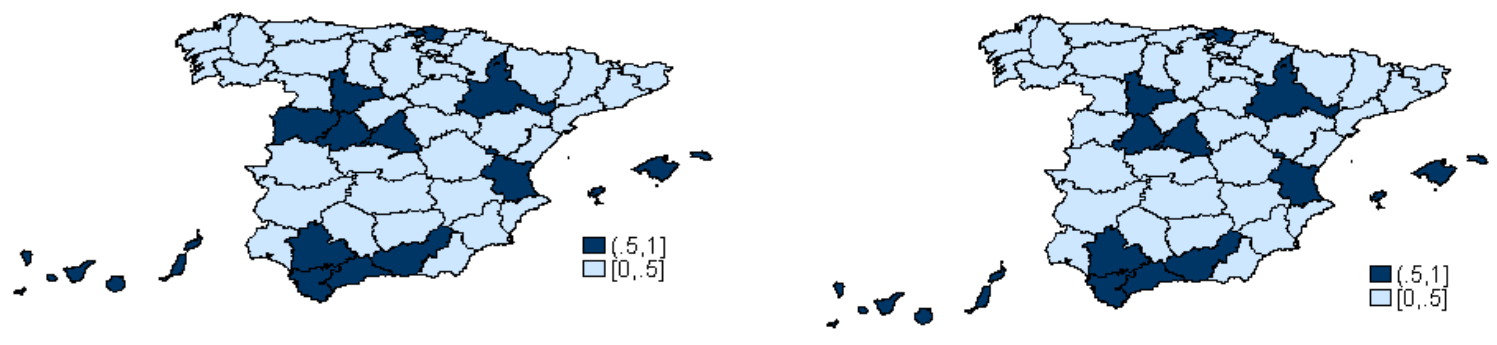


Figure 4. Overall industrial mix and regional share and province classification for employment growth

Pre-crisis period: 2002:1 and 2008:2

Post crisis period: 2008:2 and 2015:4
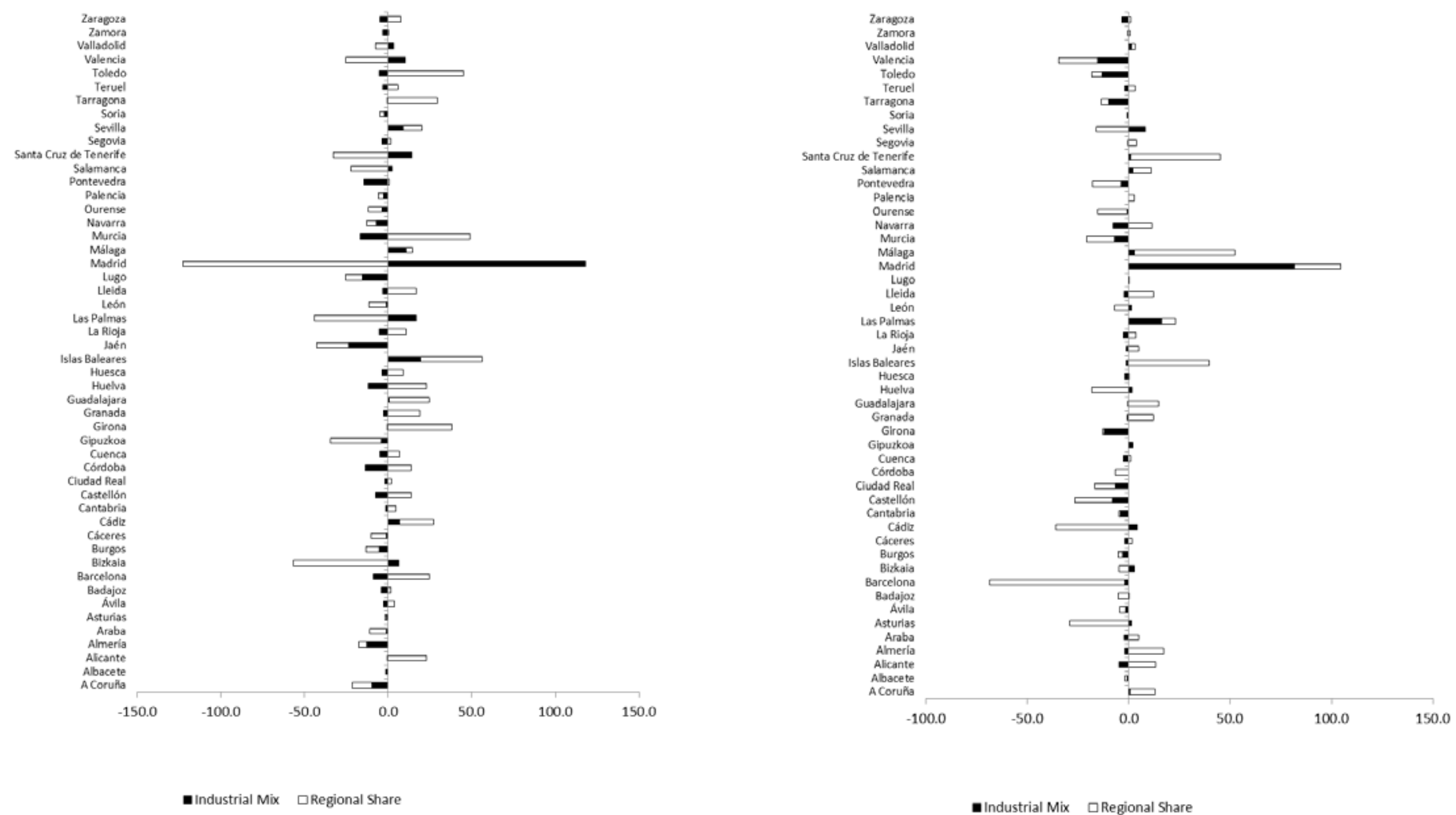

Figure 5. Changes between category classification between pre- and post- crisis period in relation to province classification attending overall Industrial Mix (IM) and Regional Share (RS)

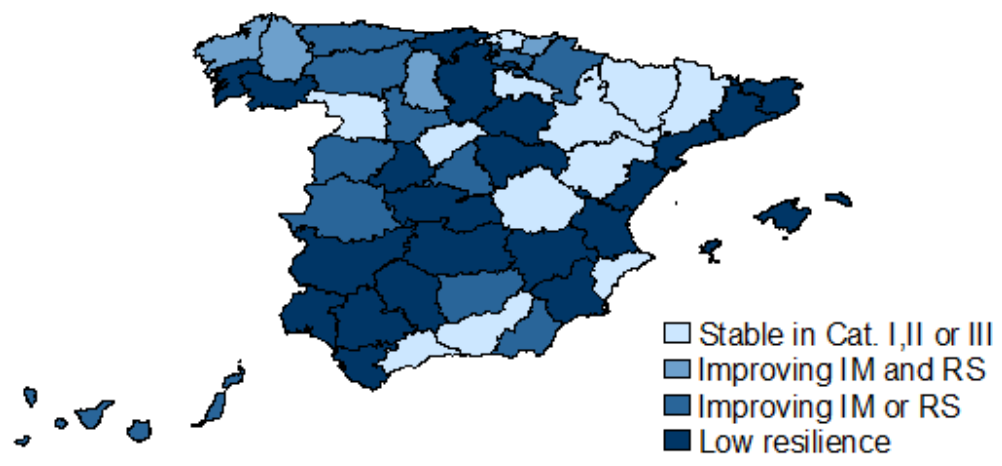


Figure 6. Net Regional Share (NRS) and Distributional Effect (DE) for employment growth.

Pre-crisis period: 2002:1 and 2008:2

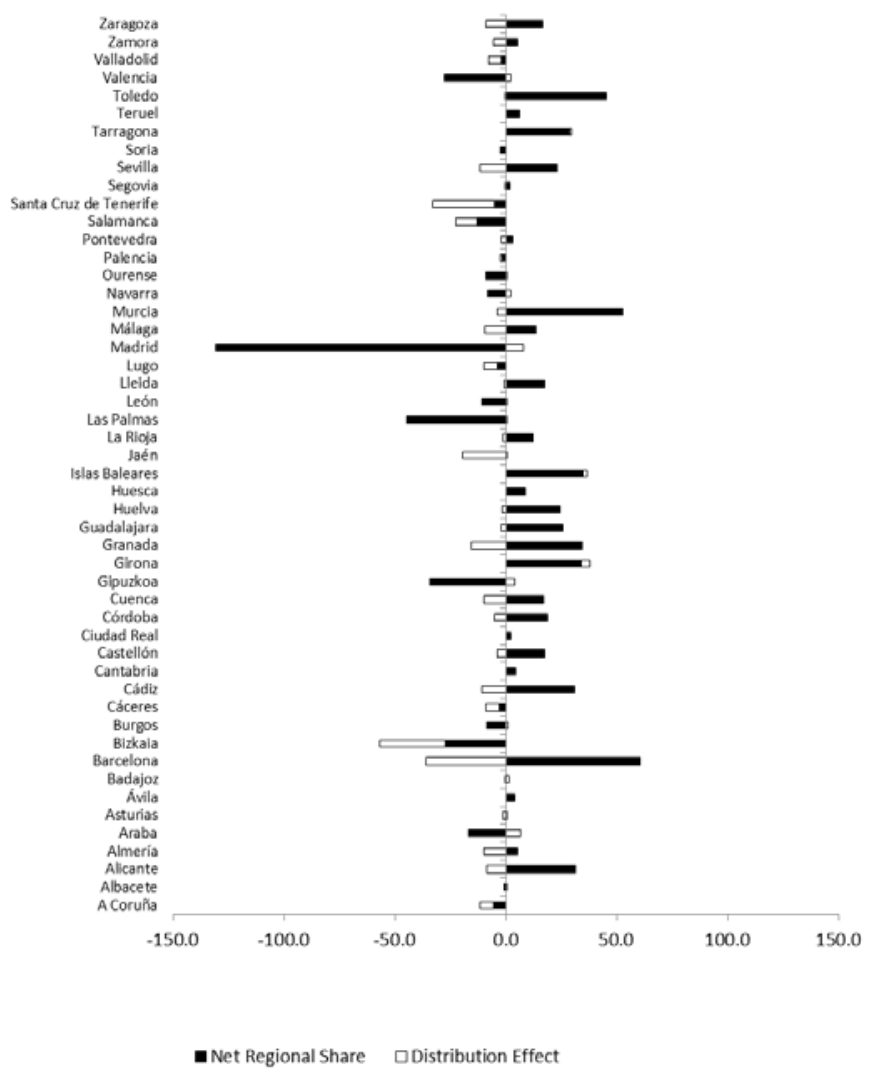

Post crisis period: 2008:2 and 2015:4

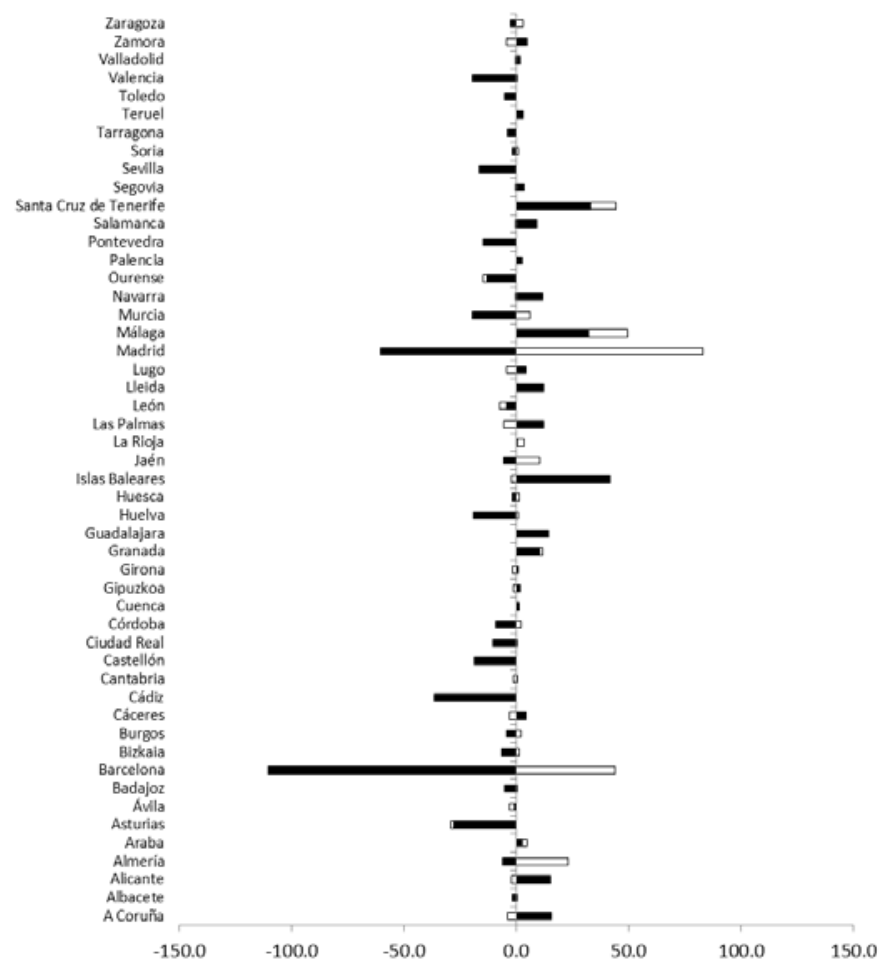

- Net Regional Share $\quad$ Distribution Effect

Figure 7. Changes between Distributional Effect (DE) sign between pre- and post- crisis period.

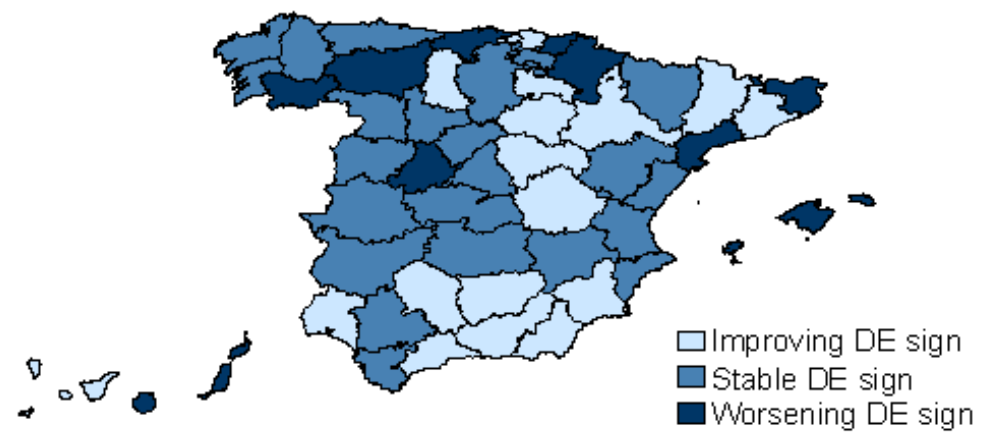


Figure 8. Provincial versus national "growth drops" after the crisis.

Figure 8a. Provincial average “Growth drops” after the crisis

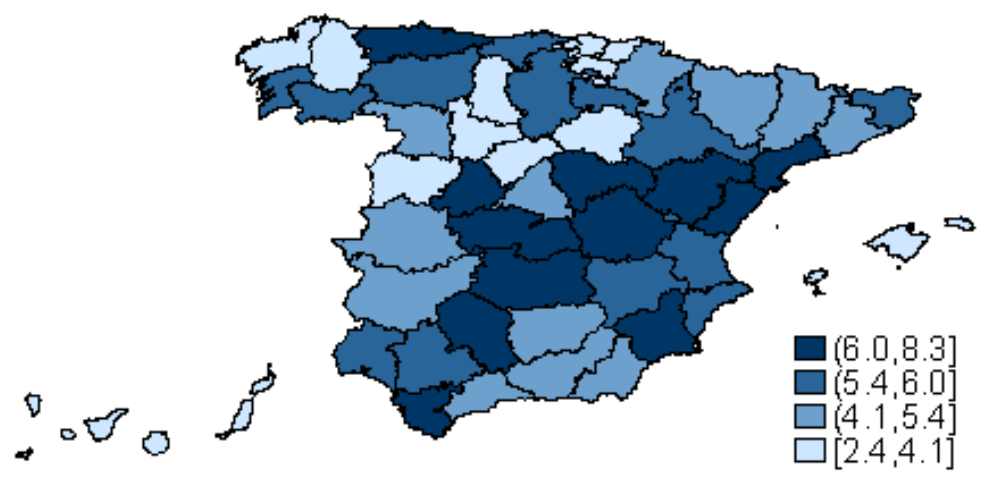

Figure 8b: Provincial versus national average "Growth drops" after the crisis

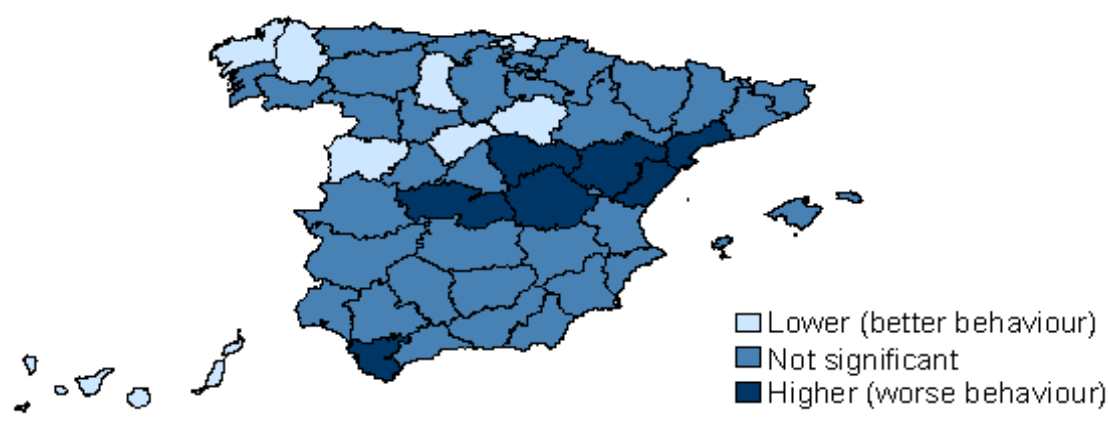




\section{APPENDIX}

Figure 1A. Mapping results shown in Figure 4 (Overall industrial mix and regional share and province classification for employment growth)
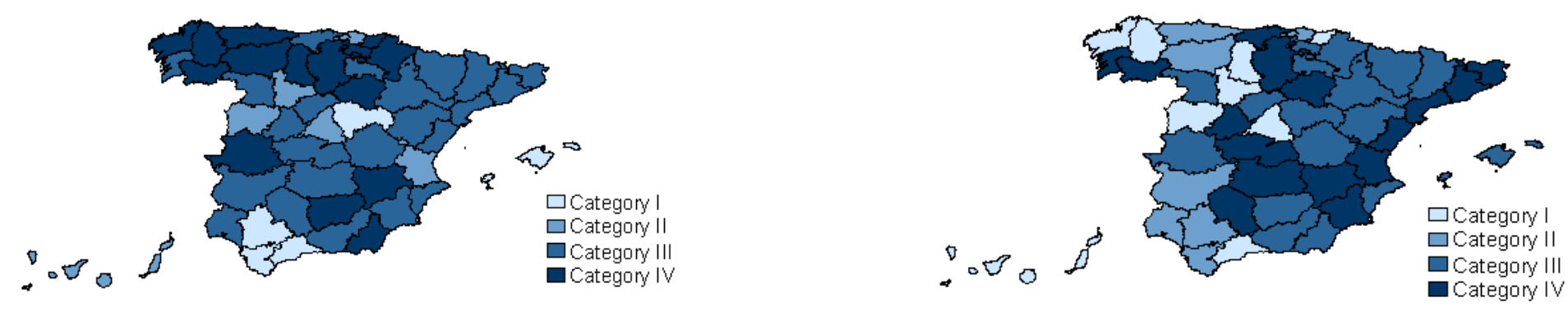

Figure 2A. Mapping of Distributional Effects (DE) show in Figure 6

Pre-crisis period: 2002:1 and 2008:2
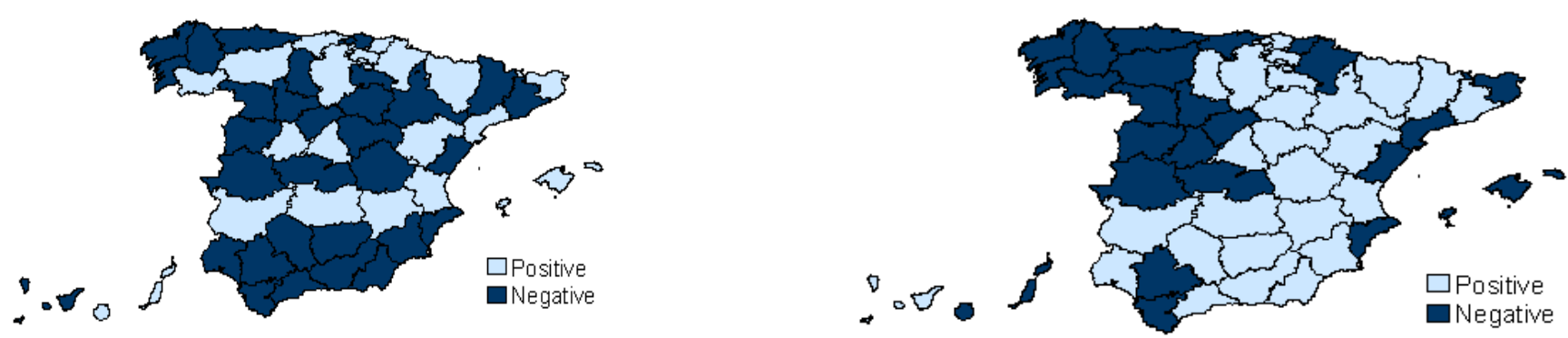